JHR

32,6

Received 1 May 2018 Accepted 23 July 2018

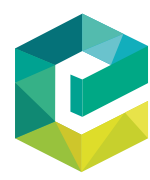

Journal of Health Research Vol. 32 No. 6, 2018 pp. $478-484$ Emerald Publishing Limited 2586-940X DOI 10.1108/JHR-11-2018-088

\section{Prevalence of cognitive impairment among hill-tribe older people in the Northern part of Thailand}

\author{
Supaporn Trongsakul \\ School of Health Science, Mae Fah Luang University, \\ Chaing Rai, Thailand \\ Thapakorn Ruanjai and Wilawan Chaiut \\ School of Health Science, Mae Fah Luang University, Chaing Rai, Thailand and \\ Center of Excellence for Hill Tribe Health Research, \\ Mae Fah Luang University, Chaing Rai, Thailand \\ Ratipark Tamornpark \\ Center of Excellence for Hill Tribe Health Research, Mae Fah Luang University, \\ Chaing Rai, Thailand, and \\ Tawatchai Apidechkul \\ School of Health Science, Mae Fah Luang University, \\ Chaing Rai, Thailand and \\ Center of Excellence for Hill Tribe Health Research, \\ Mae Fah Luang University, Chaing Rai, Thailand
}

\begin{abstract}
Purpose - The purpose of this paper is to investigate the prevalence and factors related to cognitive impairment among hill-tribe older people in Chiang Rai province, Thailand.

Design/methodology/approach - A cross-sectional study was carried out amongst 459 hill-tribe older people aged 60 years and above. A Mini Mental State Examination (MMSE) Thai 2002 version was used for cognitive screening. A questionnaire and medical records were used for demographic and clinical data collection while descriptive statistics were used to analyze characteristic data. Potential factors related to cognitive impairment were analyzed by using univariate logistic regression analysis.

Findings - The prevalence of cognitive impairment amongst the participants was 49.89 percent (95\% CI $45.32 \%, 53.47$ percent). Factors related to cognitive decline included no occupation $(\mathrm{OR}=1.49$, $95 \%$ CI $1.10-2.03, p<0.04)$ and a history of amphetamine use ( $\mathrm{OR}=1.57,95 \%$ CI $1.09-2.33, p<0.04)$.

Originality/value - Cognitive decline should be a cause for concern amongst Thai hill-tribe older people, especially amongst those in the group with a history of amphetamine use. However, Thai health care professionals need to be aware of the potential cultural bias in the MMSE Thai 2002 version as a cognition test targeted at the hill-tribe population as the questionnaire may not provide a true reflection of their cultural experience and background.
\end{abstract}

Keywords Cognitive impairment, Hill-tribe older people, Thailand

Paper type Short report

(c) Supaporn Trongsakul, Thapakorn Ruanjai, Wilawan Chaiut, Ratipark Tamornpark and Tawatchai Apidechkul. Published in Journal of Health Research. Published by Emerald Publishing Limited. This article is published under the Creative Commons Attribution (CC BY 4.0) licence. Anyone may reproduce, distribute, translate and create derivative works of this article (for both commercial and non-commercial purposes), subject to full attribution to the original publication and authors. The full terms of this licence may be seen at $\mathrm{http} / / /$ creativecommons.org/licences/by/4.0/legalcode 


\section{Introduction}

Like many countries worldwide, Thailand's ageing population is rapidly increasing. A Thai older person is defined as aged 60 years and above. It is anticipated that their numbers will increase from $11 \mathrm{~m}$ in 2015 to $23 \mathrm{~m}$ by 2050[1]. Chronic diseases are the main problem amongst the older population. Thus, the problems of self-care and restrictions to performing activities of daily living (ADL) rise sharply amongst this group. One of the crucial chronic diseases in old age is cognitive impairment and dementia[2] that is known to be a leading cause of disability amongst older people worldwide[3]. The disease affects memory, thinking, behavior and the ability to perform ADL. These difficulties lead to reduced quality of life in old age as well as a burden for carers and family members in the long term[2].

With the improvement of primary care services in Thailand over the past 20 years, basic health care and medical services can now reach people in remote areas, especially the hill-tribe people who are an ethnic minority group in Thailand[4]. Although they are scattered over 20 western and northern border provinces in Thailand, 90 percent reside in the Northern provinces[5]. Chiang Rai, the northernmost province of Thailand, is one of the provinces with the highest proportion of Thailand's hill-tribe population, consisting of six main ethnic groups: Akha, Lahu, Lisu, Hmong, Yao and Karen. Each ethic group can be identified by their unique traditional attire and languages $[4,5]$. The number of older hill tribe people is also increasing as they live longer[6]. Moreover, with the development of the Thai economy, modern lifestyles begin to have a significant impact on the health of hill-tribe people. Recent surveys showed that the hill-tribe older population are experiencing chronic disease problems such as hypertension, a problem commonly found amongst Thai older people[7].

The prevalence of cognitive impairment and dementia in Thailand ranges from 17 to 55 percent[8]. This wide statistical variation is due to the difference of study areas, research designs and tools. The latest data from the fifth survey of the Thai National Health Examination, that used the Mini Mental State Examination (MMSE) Thai 2002 as a cognitive screening tool, reported that the prevalence rate of dementia in older people from all regions of Thailand is 8 percent[9]. Nonetheless, previous studies on cognitive impairment and dementia in Thailand had not included hill-tribe people who live in remote areas and are settled in Thailand for a long time.

The prevalence of the problem amongst the hill tribe older people should not be neglected and appropriate planning and prevention schemes should be put in place to support them into the future. Our study aimed to determine the prevalence and potential associated factors related to cognitive impairment in older hill tribe people who live in Chiang Rai province. The results of this study will be useful primary data to enhance health care services as well as in the establishment of other related health studies amongst the hill tribe people.

\section{Methods}

A cross-sectional study was carried out in the five districts of Chiang Rai province between March and October 2016. A simple random sampling technique by computer program was used to select the study site and participants. A minimum of 100 eligible participants per district were recruited. Potential participants included hill-tribe people aged 60 years old and above who were fluent in speaking Thai with no impairment of communication and hearing. Participants were excluded if they had a history of stroke or were receiving medical treatment with psychoactive drugs, could not communicate in Thai or had hearing loss. In total, 459 older hill-tribe people were assessed for cognitive impairment by using the MMSE Thai 2002 version. All participants provided informed consent before being assessed for inclusion in the study. Demographic data were obtained via interview questionnaires. Ethical approval was obtained from the Research Ethical
Prevalence of cognitive impairment 
JHR

32,6

480

Committees of Mae Fah Luang University (No. REH-58087). The following independent factors were included in univariate analysis: age, gender, tribe, marital status, education, living arrangements, occupation, health behaviors and chronic diseases. The dependent factor was cognitive impairment. Descriptive statistics were used to analyze characteristics and potential factors related to cognitive impairment that were analyzed by using univariate logistic regression analysis.

\section{Cognitive screening tool}

The MMSE Thai 2002 is a current clinical mainstay cognitive screening instrument in Thailand[10]. It has been used to detect cognitive impairment to follow the course of an illness and to monitor response to treatment[11]. The MMSE Thai 2002 consists of 11 item-tests based on a total score of 30 , with a cut-off score of 14 for an illiterate person (sensitivity $=0.35$, specificity $=0.81$ ), 17 for those who only completed primary school (sensitivity $=0.57$, specificity $=0.94$ ) and 22 for those who completed secondary school or higher education (sensitivity $=0.92$, specificity $=0.93$ )[11]

\section{Results}

As shown in Table I, there were 459 participants, 232 (50.5 percent) of them were females and 227 (49.5 percent) were males. A similar pattern of gender representation was found in both groups of no cognitive impairment and possible cognitive impairment. There were 117 (50.9 percent) females in the group with no cognitive impairment and 115 (50.2 percent) females in the group with possible cognitive impairment. Likewise, males represented 113 (49.1 percent) in the group with no cognitive impairment and 114 (49.8 percent) in the group with possible cognitive impairment. The highest proportion of participants belonged to the 60-69 year old age group (51.9 percent). Akha and Karen tribes were the highest number of participants at 80 (17.4 percent) and 81 (17.6 percent), respectively. This study showed that there were no statistically significant differences in gender, age group and tribe between the two groups (with and without cognitive impairment). In total, 432 (94.1 percent) of all the participants in the groups with and without cognitive impairment were illiterate. The percentage of participants who attended primary school was found to be the same between the group without cognitive impairment 13 (5.7 percent) and the group with cognitive impairment 14 (6.1 percent), with no statistically significant differences $(p=0.834) .426$ (92.8 percent) participants lived with their children. Furthermore, clinical characteristics showed that only 45 (9.8 percent) participants had diabetes and 147 (32.0 percent) participants had hypertension. A total of 95 (20.7 percent) and 78 (17.0 percent) participants were smoking and drinking respectively. Overall, health behaviors (smoking and drinking) and the prevalence of chronic diseases (diabetes and hypertension) between the two groups (with and without cognitive impairment) displayed no statistically significant differences.

Nevertheless, the data showed that the number of people who were still working with no cognitive impairment was higher than the group who were still working with possible cognitive impairment (158 vs 135$)$ with a statistically significant difference $(p=0.03)$. In addition, the data of participants who had a history of amphetamine use between the two groups (with and without cognitive impairment) showed a statistically significant difference at $p=0.039$.

\section{Prevalence of cognitive impairment}

The result from this study shows that the prevalence of cognitive impairment revealed by the MMSE Thai 2002 test was 49.89 percent (95\% CI 45.32-53.47 percent). 


\begin{tabular}{|c|c|c|c|c|c|}
\hline Characteristics & $\begin{array}{c}\text { No cognitive impairment } \\
(n=230)\end{array}$ & $\begin{array}{l}\text { Possible cognitive impairment } \\
\qquad(n=229)\end{array}$ & Total & $p$-value & $\begin{array}{r}\text { Prevalence of } \\
\text { cognitive }\end{array}$ \\
\hline \multicolumn{5}{|l|}{ Gender } & \multirow{3}{*}{ impairment } \\
\hline Male & $113(49.1 \%)$ & $114(49.8 \%)$ & $227(49.5 \%)$ & \multirow[t]{2}{*}{0.889} & \\
\hline Female & $117(50.9 \%)$ & $115(50.2 \%)$ & $232(50.5 \%)$ & & \\
\hline \multicolumn{5}{|l|}{ Age (years) } & \multirow[t]{3}{*}{481} \\
\hline $70-79$ & $\begin{array}{r}114(49.6 \%) \\
85(37.0 \%)\end{array}$ & $\begin{array}{r}124(54.1 \%) \\
75(32.8 \%)\end{array}$ & $160(34.9 \%)$ & \multirow{2}{*}{0.589} & \\
\hline$>80$ & $31(13.5 \%)$ & $30(13.1 \%)$ & $61(13.3 \%)$ & & \\
\hline \multicolumn{5}{|l|}{ Tribes } & \\
\hline Ahka & $39(17.0 \%)$ & $41(17.9 \%)$ & $80(17.4 \%)$ & \multirow[t]{6}{*}{0.185} & \\
\hline Lahu & $32(13.9 \%)$ & $45(19.7 \%)$ & $77(16.8 \%)$ & & \\
\hline Mong & $41(17.8 \%)$ & $33(14.4 \%)$ & $74(16.1 \%)$ & & \\
\hline Yao & $34(14.8 \%)$ & $35(15.3 \%)$ & $69(15.0 \%)$ & & \\
\hline Karen & $49(21.3 \%)$ & $32(14.0 \%)$ & $81(17.6 \%)$ & & \\
\hline Lisu & $35(15.2 \%)$ & $43(18.8 \%)$ & $78(17 \%)$ & & \\
\hline \multicolumn{5}{|c|}{ Living arrangement } & \\
\hline Alone & $22(90.4 \%)$ & $11(95.2 \%)$ & $33(7.2 \%)$ & \multirow[t]{2}{*}{0.056} & \\
\hline Not alone & $208(9.6 \%)$ & $218(4.8 \%)$ & $426(92.8 \%)$ & & \\
\hline \multicolumn{5}{|l|}{ Occupation } & \\
\hline Yes & $158(68.7 \%)$ & $135(59.0 \%)$ & $293(63.8 \%)$ & \multirow[t]{2}{*}{$0.030^{*}$} & \\
\hline No & $72(31.3 \%)$ & $94(41.0 \%)$ & $166(36.2 \%)$ & & \\
\hline \multicolumn{5}{|l|}{ Education } & \\
\hline Illiterate & $217(94.3 \%)$ & $215(93.9 \%)$ & $432(94.1 \%)$ & \multirow[t]{5}{*}{0.834} & \\
\hline Primary school & $13(5.7 \%)$ & $14(6.1 \%)$ & $27(5.9 \%)$ & & \\
\hline Smoking & & & & & \\
\hline Yes & $49(21.3 \%)$ & 46 (20.1\%) & $95(20.7 \%)$ & & \\
\hline No & $181(78.7 \%)$ & $183(79.9 \%)$ & $364(79.3 \%)$ & & \\
\hline \multicolumn{5}{|l|}{ Drinking } & \\
\hline Yes & $45(19.6 \%)$ & $33(14.4 \%)$ & $78(17.0 \%)$ & & \\
\hline No & $185(80.4 \%)$ & $196(85.6 \%)$ & $381(83.0 \%)$ & & \\
\hline \multicolumn{5}{|c|}{ History of amphetamine use } & \\
\hline Yes & $10(4.3 \%)$ & $2(0.8 \%)$ & $12(2.6 \%)$ & \multirow[t]{2}{*}{$0.039^{*}$} & \\
\hline No & $220(95.7 \%)$ & $227(99.1 \%)$ & $447(97.4 \%)$ & & \\
\hline \multicolumn{5}{|l|}{ Diabetes } & \\
\hline Yes & $22(9.6 \%)$ & $23(10.0 \%)$ & $45(9.8 \%)$ & \multirow[t]{2}{*}{0.863} & \\
\hline No & $208(90.4 \%)$ & $206(90.0 \%)$ & $414(90.2 \%)$ & & \\
\hline \multicolumn{5}{|l|}{ Hypertension } & \multirow{4}{*}{$\begin{array}{r}\text { Table I. } \\
\text { Summary of the } \\
\text { participants } \\
\text { characteristics }\end{array}$} \\
\hline Yes & $73(31.7 \%)$ & $74(32.3 \%)$ & $147(32.0 \%)$ & 0.895 & \\
\hline No & $157(68.3 \%)$ & $155(67.7 \%)$ & $312(68.0 \%)$ & & \\
\hline \multicolumn{5}{|c|}{ Notes: $n=459 . * p \leqslant 0.05$} & \\
\hline
\end{tabular}

Potential associated factors with cognitive impairment

Table II displaying the univariate logistic regression revealed that the characteristics of participants who were more likely to be reported as having possible cognitive impairment were those with no occupation (OR $=1.49,95 \%$ CI 1.10, 2.03) and had a history of amphetamine use (OR $=1.57,95 \%$ CI 1.09-2.33). 
JHR

32,6

482

\section{Discussion}

The results of this study showed a higher percentage of cognitive impairment compared to the national survey which used the same screening tool as ours. The higher prevalence may be due to true higher clinical prevalence or the limitation of MMSE in those with limited education $[12,13]$ in our population. In addition, the national survey tended to screen in urban areas with a better educated population than the hill-tribe people. Moreover, the MMSE Thai 2002 is highly specific but less sensitive in identifying cognitive impairment, particularly amongst illiterate subjects (sensitivity $=0.35$, specificity $=0.81)[11]$. Nevertheless, it has been used as a clinical screening tool in Thailand and it is most often used as a known reference standard against which other cognitive screening tests are compared and has the major advantage of being widely understood[14].

Regarding the deterioration of physical health, no occupation or unemployment is common amongst the hill-tribe older people as they can no longer work and have to stay at home. The loss of income and independence combined with loneliness are factors that could trigger depressive symptoms which overlap with early dementia[15]. Depression and dementia share many similar symptoms, including memory problems, insomnia and lack of motivation, so it can be difficult to tell the two diseases apart[16]. This highlights the limitation of this study which focused on the prevalence of cognitive impairment while studies on the status of the participant's depressive mood was not definitely excluded. This means that the results of cognitive impairment could have been influenced by the presence of an underlying depressive condition and vice versa.

Mental health study amongst the older hill-tribe community of Thailand is scarce. A study from Nammongkol[17] reported that the two common problems which were raised in the hill-tribe community were financial and drug abuse related problems. Nammongkol's study[17] also revealed that amphetamine was commonly used in hill-tribe communities, particularly between 1994 and 1998. Hill-tribe villages located in remote areas far from government control and close to drug trafficking routes at the borders have high numbers of drug abusers[18]. In total, 95 (20.7 percent) participants in this study had a history of amphetamine use and 59 percent showed signs of cognitive impairment. It is possible that the older hill-tribe people with chronic use of amphetamine may experience cognitive dysfunction, especially at the frontal-executive function[19].

There are many cognitive screening tests in the Thai language which need formal knowledge to respond to the tests. Although the Thai version of Informant Questionnaire on Cognitive Decline in the Elderly (IQCODE)[20, 21] is one of the cognitive screening tests which could be applied by interviewing the informant such as a family member or carer who knows the patient's behavior well, it is impractical for routine use in the primary care setting, particularly in remote areas where many people visit the doctor without appointment each day and informants of older patients are not always available. However, from our experience of dealing with data collection, we believe that the MMSE Thai 2002 is best used in combination with another screening tool.

Table II.

Potential associated factors related to cognitive impairment among hill-tribe older people 


\section{Conclusion}

This study revealed the high number of hill-tribe older people with potential cognitive impairment. In addition, it shows that hill-tribe older people who were not working or who had previously used amphetamine may have a higher chance of developing cognitive impairments. It is possible that substance abuse among hill-tribe elderly in the past may be a cause of cognitive impairment that is often overlooked. Thus, this is the first study to investigate the prevalence of cognitive impairment among Thai older hill-tribe people and highlights the awareness of cognitive decline in this population. It is recommended that public health education and health promotion programs should also be concerned with dementia risk factors amongst this population.

\section{References}

1. Knodel J, Teeraichitchainan B, Prachuabmoh V, Pothsiri N. The situation of Thailand's older population: an update based on the 2014 survey of older persons in Thailand. Population Studies Center Report 15-847, Institute of Social Research, University of Michigan; 2015. [cited 2018 Apr 18]. Available from: www.psc.isr.umich.edu

2. World Health Organization [WHO]. Mental health and older adults. [cited 2018 Apr 1]. Available from: www.who.int/mediacentre/factsheets/fs381/en/

3. The Lancet editorial. Life, death, and disability in 2016. The Lancet. 2017; 390(10100): 1083. doi: 10.1016/S0140-6736(17)32465-0

4. Apidechkul T, Wongnuch P, Sittisarn S, Ruanjai T. Health situation of Akha Hill Tribe in Chiang Rai province, Thailand. J Public Health \& Development. 2016 Jan-Apr; 14(1): 77-97.

5. Hope for Hilltribes. Understanding the problem. 2018. [cited 2018 Apr 1]. Available from: www. hopeforhilltribes.org/problem.html

6. The United Nations Children's Fund [UNICEF] Thailand. Situation analysis of children and women in Thailand 2011. [cited 2018 Apr 1]. Available from: www.unicef.org/thailand/1045_UNICEF_ Final_row_res_230911.pdf

7. Duangtep Y, Narksawat K, Chongsuwat R, Rojanavipart P. Association between an unhealthy lifestyle and other factors with hypertension among hill tribe populations of Mae Fah Luang District, Chiang Rai Province, Thailand. Southeast Asian J Trop Med Public Health. 2010 May; 41(3): 726-34.

8. Lasuka D. Dementia in Thailand: current situation. [cited 2018 Apr 17]. Available from: https://ir. library.osaka-u.ac.jp/repo/ouka/all/50050/glocol15_043.pdf

9. Akeplakorn W, Pakchareon H, Thaikra K, Satiennoppakaw W. The Thai National Health Examination Survey V, 2014. Bangkok: Health System Research Institute; 2016 (in Thai).

10. Thai Prasat Neurological Institute. Clinical practice guideline for dementia. Bangkok: Thai Prasat Neurological Institute; 2008 (in Thai).

11. Ageingthai. The comparison between MMSE Thai 2002 and TMSE for screening dementia. Nonthaburi: Ministry of Public Health; 2008 (in Thai).

12. Devenney E, Hodges JR. The Mini-Mental State Examination: pitfalls and limitations. Pract Neurol. 2017 Jan; 17(1): 79-80. doi: 10.1136/practneurol-2016-001520

13. Wongchaisuwan T, Sithinamsuwan P, Udommongkol C, Wongmek W. Factors influencing MMSE-T score among Thai subjects. J Med Assoc Thai. 2005 Nov; 88(S3): S155-8.

14. Iatraki E, Simos PG, Bertsias A, Duijker G, Zaganas I, Tziraki C, et al. Cognitive screening tools for primary care settings: examining the "Test Your Memory" and "General Practitioner assessment of Cognition" tools in a rural aging population in Greece. Eur J Gen Pract. 2017 Dec; 23(1): 171-8. doi: 10.1080/13814788.2017.1324845

15. Lindgren BM, Sundbaum J, Eriksson M, Graneheim UH. Looking at the world through a frosted window: experiences of loneliness among persons with mental ill-health. J Psychiatr Ment Health Nurs. 2014 Mar; 21(2): 114-20. doi: 10.1111/jpm.12053 
16. Mirza SS, Wolters FJ, Swanson SA, Koudstaal PJ, Hofman A, Tiemeier H, et al. 10-year trajectories of depressive symptoms and risk of dementia: a population-based study. Lancet Psychiatry. 2016 Jul; 3(7): 628-35. doi: 10.1016/s2215-0366(16)00097-3

17. Nammongkol M, Mudtam U, Pasaranun P. Hill-tribe mental health survey 1999. Proceeding of the 7th Department of Mental Health, Ministry of Public Health, Nonthaburi, Thailand. Nonthaburi; 2001 Sep 5-7.

18. Angkurawaranon C, Jiraporncharoen W, Likhitsathian S, Thaikla K, Kanato M, Perngparn U, et al. Trends in the use of illicit substances in Thailand: results from national household surveys. Drug Alcohol Rev. 2018 Jul; 37(5): 658-63. doi: 10.1111/dar.12689

19. Wood S, Sage JR, Shuman T, Anagnostaras SG. Psychostimulants and cognition: a continuum of behavioral and cognitive activation. Pharmacol Rev. 2014; 66(1): 193-221. doi: 10.1124/ pr.112.007054

20. Senanarong V, Assavisaraporn S, Sivasiriyanonds N, Printarakul T, Jamjumrus P, Udompunthuruk S, et al. The IQCODE: an alternative screening test for dementia for low educated Thai elderly. J Med Assoc Thai. 2001 May; 84(5): 648-55.

21. Harrison JK, Fearon P, Noel-Storr AH, McShane R, Stott DJ, Quinn TJ. Informant Questionnaire on Cognitive Decline in the Elderly (IQCODE) for the diagnosis of dementia within a secondary care setting. Cochrane Database Syst Rev. 2015 Mar; 10(3): doi: 10.1002/14651858.CD010772.pub2

\section{Corresponding author}

Supaporn Trongsakul can be contacted at: supaporn.tro@mfu.ac.th

For instructions on how to order reprints of this article, please visit our website: 